\title{
Impact of Sex and Menopausal Status on Episodic Memory Circuitry in Early Midlife
}

\author{
-Emily G. Jacobs, ${ }^{1,2,3,4}$ Blair K. Weiss, ${ }^{2}$ Nikos Makris, ${ }^{3,4}$ Sue Whitfield-Gabrieli, ${ }^{5}$ Stephen L. Buka, ${ }^{6}$ Anne Klibanski, \\ and Jill M. Goldstein ${ }^{1,2,3,4}$ \\ 'Division of Women's Health, Department of Medicine and 2Department of Psychiatry, Brigham and Women's Hospital, Boston, Massachusetts 02120, \\ ${ }^{3}$ Harvard Medical School, Boston, Massachusetts 02120, ${ }^{4}$ Athinoula A. Martinos Center, Massachusetts General Hospital, Charlestown, Massachusetts \\ 02129, ${ }^{5}$ Department of Brain and Cognitive Sciences, Massachusetts Institute of Technology, Cambridge, Massachusetts 02139, ${ }^{6}$ Department of \\ Epidemiology, Brown University School of Public Health, Providence, Rhode Island 02903, and ${ }^{7}$ Neuroendocrine Unit, Department of Medicine, \\ Massachusetts General Hospital, Boston, Massachusetts 02114
}

Cognitive neuroscience of aging studies traditionally target participants age 65 and older. However, epidemiological surveys show that many women report increased forgetfulness earlier in the aging process, as they transition to menopause. In this population-based fMRI study, we stepped back by over a decade to characterize the changes in memory circuitry that occur in early midlife, as a function of sex and women's reproductive stage. Participants $(N=200$; age range, $45-55)$ performed a verbal encoding task during fMRI scanning. Reproductive histories and serologic evaluations were used to determine menopausal status. Results revealed a pronounced impact of reproductive stage on task-evoked hippocampal responses, despite minimal difference in chronological age. Next, we examined the impact of sex and reproductive stage on functional connectivity across task-related brain regions. Postmenopausal women showed enhanced bilateral hippocampal connectivity relative to premenopausal and perimenopausal women. Across women, lower $17 \beta$ estradiol concentrations were related to more pronounced alterations in hippocampal connectivity and poorer performance on a subsequent memory retrieval task, strongly implicating sex steroids in the regulation of this circuitry. Finally, subgroup analyses revealed that high-performing postmenopausal women (relative to low and middle performers) exhibited a pattern of brain activity akin to premenopausal women. Together, these findings underscore the importance of considering reproductive stage, not simply chronological age, to identify neuronal and cognitive changes that unfold in the middle decades of life. In keeping with preclinical studies, these human findings suggest that the decline in ovarian estradiol production during menopause plays a significant role in shaping memory circuitry.

Key words: episodic memory; estradiol; fMRI; hippocampus; menopause; PFC

Significance Statement

Maintaining intact memory function with age is one of the greatest public health challenges of our time, and women have an increased risk for memory disorders relative to men later in life. We studied adults early in the aging process, as women transition into menopause, to identify neuronal and cognitive changes that unfold in the middle decades of life. Results demonstrate regional and network-level differences in memory encoding-related activity as a function of women's reproductive stage, independent of chronological age. Analyzing data without regard to sex or menopausal status obscured group differences in circuit-level neural strategies associated with successful memory retrieval. These findings suggest that early changes in memory circuitry are evident decades before the age range traditionally targeted by cognitive neuroscience of aging studies.

\section{Introduction}

Our society is rapidly aging (Howden and Meyer, 2010), and three out of four older adults report problems with their memory

Received March 22, 2016; revised Aug. 5, 2016; accepted Aug. 8, 2016.

Author contributions: E.G.J. and J.M.G. designed research; E.G.J. and B.W. performed research; N.M., S.W.-G.,

S.B., and A.K. contributed unpublished reagents/analytic tools; E.G.J. and B.W. analyzed data; E.G.J. and J.M.G. wrote the paper.

This work was supported by NIMH Grant MH090291 (J.M.G.); the Office of Research on Women's Health and NICHD Building Interdisciplinary Research Careers in Women's Health program, Grant K12 HD051959 (E.G.J.); and the Harvard Clinical and Translational Science Center (NIH Grant UL1 RR025758). We thank Harlyn Aizley for admin-
(Koivisto et al., 1995). Thus, maintaining intact memory function with age may be one of the greatest public health challenges of our time. Intervening early with high-risk individuals is critical

istering structured clinical interviews, Anne Remington for project administration, Katie Lancaster and Julia Longenecker for help with data collection, and Dr. Shalendar Bhasin for overseeing mass spectrometry.

The authors declare no competing financial interests.

Correspondence should be addressed to either Dr. Jill M. Goldstein or Dr. Emily G. Jacobs, Brigham and Women's Hospital, Harvard Medical School, 1 Brigham Circle, Boston, MA 02120. E-mail: jill_goldstein@hms.harvard.edu or emily.jacobs@psych.ucsb.edu.

DOI:10.1523/JNEUROSCI.0951-16.2016

Copyright $\odot 2016$ the authors $\quad 0270-6474 / 16 / 3610163-11 \$ 15.00 / 0$ 
for the attenuation and prevention of disability, but early targets for treatment have not been identified. Given evidence that women are at a higher risk for memory disorders than men later in life (Gao et al., 1998; Mielke et al., 2014), applying a sexdependent lens to the study of memory circuitry aging may help identify early antecedents of future memory decline. Moreover, studying adults early in the aging process, as women transition into menopause, may reveal sex-dependent characteristics underlying the aging of memory circuitry in the middle decades of life. Substantial evidence from animal studies indicates that sex steroid hormones, including $17 \beta$-estradiol, influence synaptic organization within the hippocampus and prefrontal cortex (PFC), regions that support episodic memory encoding (Bailey et al., 2011; Boulware et al., 2012). Despite clear implications for human health, less is known about the role of sex steroids in the aging of memory circuitry at a human cognitive neuroscience level.

Verbal memory encoding is thought to rely on the coordinated activity of neurons in a distributed set of brain regions, including the hippocampus and other medial temporal lobe structures, ventrolateral and dorsolateral PFC, and posterior parietal cortex (PPC; Buckner et al., 1999; Uncapher et al., 2006; Blumenfeld and Ranganath, 2007; Spaniol et al., 2009; Cabeza and Dennis, 2012). Age-related changes in neural activity during memory encoding are well established (Morrison and Baxter, 2012; Reuter-Lorenz and Park, 2010; Grady and Craik, 2000; Morcom et al., 2003; Rajah et al., 2015), with healthy older adults typically showing altered responses in PFC and hippocampus relative to younger adults. A distinct characteristic of these two regions is that they are densely populated with sex steroid hormone receptors, including estrogen receptors $\alpha$ and $\beta$ (ER- $\alpha$ and ER- $\beta$ ).

Two decades of experimental evidence in rodents have established estradiol's role in hippocampal structural plasticity (Woolley and McEwen, 1994; McEwen 2002; Brinton 2009; Dimitriu et al., 2010; Liu et al., 2008). For example, dendritic spine density in hippocampal CA1 neurons varies over the course of the estrous cycle (Woolley et al., 1990; Woolley and McEwen, 1993), and ovariectomization leads to a $30 \%$ loss in spine density, which is reversed by estradiol replacement (Dimitriu et al., 2010). In nonhuman primates, natural menopause reduces the density of perforated synapse spines, which is correlated with worse recognition memory (Hara et al., 2012). Previous findings at the epigenetic level suggest that estradiol shapes hippocampal-dependent memory in part by inducing chromatin modifications that promote hippocampal plasticity (Fortress and Frick, 2014). In parallel, nonhuman primate studies have made substantial progress toward characterizing the role of estradiol in PFC synaptic plasticity and PFC-mediated cognitive functions (Hao et al., 2006; Morrison et al., 2006; Wang et al., 2010; Rapp et al., 2003). Mounting evidence from human neuroimaging studies further implicates sex steroids in the regulation of memory circuitry (Berman et al., 1997; Shaywitz et al., 1999; Duff and Hampson, 2000; Sherwin, 2003; Grigorova et al., 2006; Dumas et al., 2010; Jacobs and D'Esposito, 2011; Epperson et al., 2012; Hampson and Morley, 2013; Shanmugan and Epperson, 2014; Jacobs et al., 2016). This research builds on the pioneering work of Berman et al. (1997) and Shaywitz et al. (1999), who used pharmacological blockade and hormone replacement techniques to illustrate estradiol and progesterone's influence on regional activity in memory circuitry.

Together, these findings provide converging evidence that functional changes in estrogen receptor-rich regions of memory circuitry are tied to ovarian status. Thus, the decline in ovarian estradiol production during the menopausal transition in women may impact specific neural circuits early in the aging process (Hogervorst et al., 2000; Adams et al., 2002; Morrison et al., 2006; Sherwin, 2006; Brinton 2009; Boulware et al., 2012; Maki and Henderson, 2012; Epperson, 2013; Jacobs et al., 2016). In this population-based functional MRI study of early midlife men and women $(N=200$; age range, $45-55)$, we demonstrate that regional and network-level changes in memory circuitry during verbal encoding are evident early in the aging process as a function sex, women's reproductive stage, and sex steroid hormone concentrations.

\section{Materials and Methods}

Subjects. Participants were selected from 17,741 pregnancies that constitute the New England Family Study (NEFS), a Boston-Providence subsidiary of the national Collaborative Perinatal Project (CPP). The NEFS is a prospective study initiated over 50 years ago to investigate prenatal and familial antecedents of pediatric, neurological, and psychological disorders of childhood (Niswander and Gordon, 1972). Pregnant women, recruited between 1959 and 1966 were representative of patients receiving prenatal care in the Boston-Providence area. In a series of studies over the last 20 years, we have followed a subset of NEFS offspring to investigate the fetal programming of adult psychiatric and general medical disorders and sex differences therein. We recently completed a study of the fetal programming of sex differences in memory circuitry aging (NIMH R01 MH090291). In this set of analyses, 200 offspring (100 males, 100 females) were recruited in early midlife, $45-55$ years of age, and completed clinical, cognitive, and neuropsychological assessments in addition to functional and structural magnetic resonance and diffusion tensor imaging (fMRI, structural MRI, Diffusion Tensor Imaging). Exclusionary criteria included any history of neurologic disease, CNS damage, head injury with loss of consciousness, endocrine disorders, heart disease, alcohol-related diseases, current or history of psychosis, other medical illnesses that may significantly alter CNS function, or any MRI contraindication. Four subjects (all men) were excluded from fMRI analyses due to excessive motion $(>15 \%$ of trials were flagged as motion outliers), and two subjects (both men) did not complete the functional runs, producing a sample of 194 (100 women). Human subjects' approval was granted by Partners Healthcare and Brown University. All volunteers gave written informed consent and were paid for their participation.

Study design and procedures. Subjects were seen at Brigham and Women's Hospital Outpatient Clinical Research Center. Women who were still menstruating were scheduled in the early follicular phase (day 3-5) of their menstrual cycle, persuant to subject report. Based on common reference ranges (Beckman Coulter), progesterone levels for $75 \%$ of premenopausal women were indicative of follicular phase testing; however, eight women had progesterone levels suggestive of luteal phase testing. Subjects fasted for $\geq 8 \mathrm{~h}$ before a morning baseline blood draw. Subjects were offered a light standardized breakfast (excluding caffeine) followed by a $1 \mathrm{~h}$ MRI scanning session. Following the scan, subjects completed a structured clinical interview, a basic neuropsychological battery, two behavioral memory tasks, family medical history, and a reproductive/menstrual cycle history administered by an experienced clinical interviewer/clinician in a private testing room.

Neuropsychological assessments. Participants completed a basic mood and neuropsychological battery that included the following: a digit span (Wechsler, 1997), a Controlled Oral Word Association Test for verbal fluency to the letters F, A, and S (FAS) and categories (Benton, 1968), the American National Adult Reading Test (Nelson, 1982), the State-Trait Anxiety Inventory, and the Profile of Moods Questionnaire (POMS). In addition, two measures of episodic memory, the 12-item Face Name Associative Memory Exam (Sperling et al., 2003; Rentz et al., 2011) and the 6-trial Selective Reminding Test (SRT; Grober et al., 2000; Lemos et al., 2014), were administered based on previous evidence of their increased sensitivity to detecting early cognitive decline (Hedden et al., 2012). Findings from these behavioral memory tasks were described in detail previously (Rentz et al., 2016). 
Endocrine assessments. Trained nurses inserted a saline-lock intravenous line in the nondominant forearm and acquired a fasting morning blood at $\sim 8: 00$ A.M. to evaluate hypothalamic-pituitary-gonadal axis hormones, including serum levels of sex steroids (estradiol, progesterone, and testosterone) and gonadotropins [follicle-stimulating hormone (FSH)]. Approximately $10 \mathrm{cc}$ of blood were collected at Brigham and Women's Hospital Center for Clinical Investigation. Samples were allowed to clot for 30-45 min, after which blood was centrifuged $(1500 \times$ $g$ for $10 \mathrm{~min}$ ) and serum was aliquoted into $2 \mathrm{ml}$ microtubes. Serum aliquots were stored at $-20^{\circ} \mathrm{C}$ for neuroendocrine evaluations and archiving. $17 \beta$-Estradiol, progesterone, and testosterone concentrations were determined via liquid chromatography-mass spectrometry at the Brigham and Women's Hospital Research Assay Core. Assay sensitivities, dynamic range, and intra-assay coefficients of variation were as follows, respectively: estradiol, $1 \mathrm{pg} / \mathrm{ml}, 1-500 \mathrm{pg} / \mathrm{ml},<5 \% \mathrm{RSD}$; progesterone, $0.05 \mathrm{ng} / \mathrm{ml}, 0.05-10 \mathrm{ng} / \mathrm{ml}, 5.75 \%$ relative standard deviation; testosterone, $1.0 \mathrm{ng} / \mathrm{dl}, 1-2000 \mathrm{ng} / \mathrm{dl}$, <2\% RSD. FSH levels were determined via chemiluminescent assay (Beckman Coulter). The assay sensitivity was $0.2 \mathrm{mIU} / \mathrm{ml}$, the dynamic range was $0.2-200 \mathrm{mIU} / \mathrm{ml}$, and the intra-assay coefficient of variation was $3.1-4.3 \%$. $17 \beta$-Estradiol values were logtransformed to achieve a normal distribution.

Menopausal staging. The timing of menopausal transition between the first clinical appearance of decreased ovarian function (i.e., shorter intermenstrual time periods) to menstrual irregularity and final amenorrhea is highly variable and can occur over several years. Women in this sample were between the ages of 45-55 years and were in various states of ovarian decline. Some women were already in menopause with permanent amenorrhea, low estradiol levels, and elevated gonadotropins; some exhibited signs of follicular failure (elevated FSH and oligoamenorrhea); and some showed normal cycling. Reproductive histories and hormonal evaluations were used to determine the reproductive stage of women in our sample following the Stages of Reproductive Aging Workshop (STRAW)-10 staging system (Harlow et al., 2012). Principal staging criteria were based on menstrual cycle characteristics, with supportive criteria provided by FSH levels. Women were categorized as late reproductive ("premenopause"; $n=32$ ), menopausal transition ("perimenopause"; $n=29$ ), or early postmenopausal ("postmenopause"; $n=31$ ). The women in our sample ranged from Stage $-3 b$, characterized by regular cycling and low FSH, to Stage $+1 \mathrm{c}$, characterized by amenorrhea and elevated FSH. An additional eight women reported current use of a hormone replacement regimen and were excluded from all analyses related to reproductive stage. Their data were included in the "supergroup" analyses of fMRI data used to generate generic, task-evoked functional regions of interest (ROIs).

Verbal encoding fMRI paradigm and subsequent memory retrieval task. Participants performed a verbal encoding task during fMRI scanning (Stone et al., 2005; Golby et al., 2001). The task consisted of two conditions, "Novel" and "Repeat." In each condition, subjects were presented with a pair of common nouns on a black background presented centrally (4000 ms duration) with a variable interstimulus interval (600-1500 $\mathrm{ms}$ ). Subjects were asked to silently generate a sentence using both words and were instructed to remember the stimuli for a later test. In the Repeat condition, subjects viewed the same noun pair repeated throughout each block of a run and were instructed to generate the same sentence each time they saw the word pair. In the Novel condition, subjects viewed novel word pairs and generated a new sentence in response to each pair. Subjects were instructed to respond to every word pair with a single button press (pointer finger) to indicate that they had successfully formed a sentence in their mind. Subjects performed two experimental runs of the task. Each run contained three Repeat blocks and three Novel blocks, for a total of six blocks per condition.

A subsequent recognition memory task was administered immediately following the encoding task using the same response box and while the subject remained in the scanner. Subjects viewed single nouns, including 24 previously presented nouns and 24 foils. Each stimulus was presented for $4000 \mathrm{~ms}$ with a variable interstimulus interval. Subjects were instructed to indicate, using one of two buttons, whether they had seen the item on the screen in the previous task (yes) or not (no). Response times $(\mathrm{RT})$ and accuracy $\left(d^{\prime}\right)$ were recorded. Response time values $<100 \mathrm{~ms}$ were considered null and not included in the computation of subjects' average RT. The sensitivity index $d^{\prime}$ was calculated (Wickens, 2001) as $d^{\prime}=z$ [probability(hits) $]-z$ [probability(false alarms) $]$. In accordance with signal detection theory, a higher $d^{\prime}$ represents a greater distinction between signal and noise (i.e., better signal detection).

fMRI data acquisition. MRI data were acquired with a Siemens 3T Tim Trio scanner equipped with a 12-channel head coil. Functional data were obtained using a $\mathrm{T}^{\star}{ }^{\star}$ weighted echoplanar imaging sequence sensitive to blood oxygenation level-dependent (BOLD) contrast (repetition time, $2000 \mathrm{~ms}$; echo time, $30 \mathrm{~ms}$; field of view, $200 \mathrm{~mm}$; flip angle, $90^{\circ}$; voxel size, $3.1 \times 3.1 \times 3.0$ ). Each functional volume consisted of $333 \mathrm{~mm}$ oblique axial slices. A T1-weighted image was collected using a high resolution 3D multiecho MPRAGE sagittal sequence with an isotropic resolution of $1 \mathrm{~mm}^{3}$. Following acquisition, MRI data were converted to Nifti format and preprocessed in SPM8 (Wellcome Department of Cognitive Neurology, London, United Kingdom). Preprocessing included realignment and geometric unwarping of echoplanar imaging images using magnetic field maps, correction for head motion, nonlinear volume-based spatial normalization (Montreal Neurological Institute template MNI-152), and spatial smoothing with a Gaussian filter $(6 \mathrm{~mm}$ full-width at half-maximum). Additional software (http://web.mit.edu/ $\mathrm{swg} / \mathrm{software} . \mathrm{htm}$ ) was used to identify and exclude outliers in the global mean image time series (threshold, 3.0 SD from the mean) and movement (threshold, $1.0 \mathrm{~mm}$; measured as scan-to-scan movement, separately for translation and rotation) parameters. Statistical parametric maps of BOLD activation were calculated in SPM8 using the general linear model approach (Worsley and Friston, 1995).

$f M R I$ data analyses. Hemodynamic responses were modeled using a gamma function and convolved with onset times of Novel and Repeat blocks to form the general linear model (GLM) at the single subject level. Outlier time points and the six rigid-body movement parameters were included in the GLM as covariates of no interest. To test a priori hypotheses targeting ROIs within memory encoding circuitry (Golby et al., 2001; Blumenfeld and Ranganath 2007; Spaniol et al., 2009; Uncapher and Wagner, 2009), we conducted ROI analyses on functionally defined masks of left dorsal/posterior VLPFC (BA44/BA45/BA9), mid-VLPFC (BA45), ventral/anterior VLPFC (BA47; MNI coordinates, -51, 20, 25; $-51,30,10$; and $-39,26,-2$, respectively), left posterior parietal cortex (BA7; $-24,-61,49 ; 10 \mathrm{~mm}$ spheres around peak loci), and anatomically defined masks of the hippocampus. Functional ROIs were defined from whole-brain analyses in the larger sample $(N=194$; see Fig. $2 B)$ based on peak task-evoked activity generated at $p<10^{-16}, T=8.99$, and $\mathrm{df}=193$. The hippocampal ROI was anatomically defined using a manually segmented MNI-152 brain (based on methods previously published by the Center for Morphometric Analysis at Massachusetts General Hospital and Harvard Medical School; Makris et al., 2013). ROIs were implemented as overlays on the SPM8 canonical brain using the Wake Forest University PickAtlas ROI toolbox for SPM (Maldjian et al., 2003). Mean $\beta$ weights from the ROIs were extracted for each participant as a function of encoding load (Novel $>$ Repeat) using the REX toolbox (WhitfieldGabrieli, 2009). For each participant and ROI, $\beta$ estimates were entered into an ANOVA with reproductive status (premenopausal, perimenopausal, postmenopausal) as a between-subjects factor, and age as a covariate. Parallel analyses were run with sex (male vs female) as the between-subjects factor.

To investigate encoding-dependent alterations in functional connectivity by reproductive status and sex, we performed psychophysiological (PPI) analyses with seeds placed in two targeted regions: the hippocampus and dorsal VLPFC (BA44/BA45/BA9). The hippocampus was a clear candidate for examining the impact of reproductive status on functional connectivity given the strong a priori evidence implicating sex steroids in the regulation of this region and the results of the univariate analyses (see Results, Regional BOLD response in VE circuitry). Second, the dorsal VLPFC region showed the highest magnitude of task-evoked activity, making it a compelling candidate for examining functional interactions with PFC. Given the left-hemisphere dominance in verbal encoding tasks (Blumenfeld and Ranganath 2007; Spaniol et al., 2009), time courses from the left VLPFC seed and left hippocampus were extracted for PPI analyses. For each participant, subject-level GLMs were constructed as 
Table 1. Demographic characteristics of the sample in women by menopausal stage and men

\begin{tabular}{|c|c|c|c|c|c|c|c|c|c|c|}
\hline \multirow[b]{2}{*}{ Characteristic } & \multicolumn{2}{|c|}{$\begin{array}{l}\text { Pre }(n=32 ; \\
\text { age range, } 46-53)\end{array}$} & \multicolumn{2}{|c|}{$\begin{array}{l}\text { Peri }(n=29 ; \\
\text { age range, 47-55) }\end{array}$} & \multicolumn{2}{|c|}{$\begin{array}{l}\text { Post }(n=31 ; \\
\text { age range, } 46-54)\end{array}$} & \multicolumn{2}{|c|}{$\begin{array}{l}\text { Men }(n=94 ; \\
\text { age range, 45-55) }\end{array}$} & \multirow[b]{2}{*}{ Fvalue } & \multirow[b]{2}{*}{$p$ value } \\
\hline & Mean & SD & Mean & SD & Mean & SD & Mean & SD & & \\
\hline Age & 49.1 & 1.5 & 49.8 & 1.9 & 50.5 & 2.2 & 50.2 & 2.3 & 2.84 & 0.04 \\
\hline BMI & 28.4 & 6.1 & 28.5 & 6.1 & 27.8 & 5.8 & 29.1 & 5.4 & 0.39 & 0.76 \\
\hline Parental SES & 5.9 & 2.1 & 5.4 & 1.9 & 5.9 & 1.9 & 5.8 & 1.8 & 0.58 & 0.63 \\
\hline Education (years) & 14.5 & 1.9 & 15.2 & 1.6 & 14.9 & 1.7 & 14.6 & 2.4 & 0.34 & 0.79 \\
\hline \multirow[t]{2}{*}{ Verbal IQ } & 119.5 & 7.8 & 115.3 & 10.7 & 115.2 & 11.2 & 116.9 & 11.0 & 1.13 & 0.34 \\
\hline & $n$ & $\%$ & $n$ & $\%$ & $n$ & $\%$ & $n$ & $\%$ & & \\
\hline Ethnicity (\% Caucasian) & 24 & 92 & 24 & 96 & 18 & 90 & 59 & 94 & & \\
\hline
\end{tabular}

Of the 200 subjects enrolled, eight women were excluded from analyses due to current hormone therapy use; four subjects were excluded due to excessive head motion ( $>15 \%$ motion outliers), and two subjects did not complete the functional scans due to claustrophobia, producing a final sample of 186. Parental socioeconomic status (SES) was a composite index of family income, education, and occupation and ranged from 1.0 (low) to 9.3 (high). Verbal IQ was estimated from the American National Adult Reading Test (Nelson, 1982). Pre, Premenopausal; Peri, perimenopausal; Post, postmenopausal.

described earlier, with the addition of the seed time course as a regressor and two additional PPI regressors (the interaction of the seed time course with the regressors for Novel and Repeat conditions). These interaction regressors are orthogonal to the task and seed regressors and describe the contribution of the interaction above and beyond the main effects of the task and seed time course (McLaren et al., 2012). VLPFC and hippocampal connectivity was measured at the single subject level by estimating the difference between the interaction of the seed time course with the regressor for Novel versus Repeat blocks. Single subject activation maps were entered into second-level random effects analysis to probe group differences in memory encoding-dependent VLPFC or hippocampal connectivity. Given extensive evidence for the involvement of posterior parietal cortices in verbal memory tasks (Uncapher and Wagner, 2009) and sex differences in PFC-PPC structural covariance (Abbs et al., 2011), we focused our analyses to examine connectivity between seed regions and PPC by applying small volume correction to a mask of the parietal lobe. The small volume correction approach in SPM8 limits voxelwise analyses to voxels within an a priori volume, defined here as any encoding-sensitive region within parietal cortex. The mask was generated by taking the conjunction of voxels that fell within an anatomical parietal mask and those that demonstrated encoding-related activity from the supergroup $(N=194)$ activity map. Parallel analyses were run with sex (male vs female) as the between-subjects factor. Connectivity between the left hippocampal seed and right hippocampus was examined by applying a small volume correction across the anatomically defined right hippocampus.

Behavioral data were analyzed with SPSS version 20.0 using ANOVAs for demographic, neuropsychological, and clinical characteristics with continuous variables where equal variance was assumed. ANCOVAs were used to asses group differences in regional BOLD responses after partialling out variance attributable to chronological age. Our strongest a priori hypothesis was that advanced reproductive stage and, in particular, the decline in $17 \beta$-estradiol concentrations would alter task-evoked activity in the hippocampus and functional connectivity from the hippocampal seed. We conducted parallel analyses in VLPFC and posterior parietal cortex, two additional key nodes in memory encoding circuitry. Spearman rank-order correlations were conducted to determine the relationship between BOLD $\beta$ values, behavioral performance, and sex steroid hormone concentrations. Correlations were bootstrapped (1000 iterations), and 95\% confidence intervals were computed. A $p<0.05$ was designated for statistical significance (any $p<0.08$ is noted for completeness).

\section{Results}

Demographic, neuropsychological, and clinical characteristics

The community-based sample was 92\% Caucasian and $8 \%$ African American. Participants were in early midlife (mean age, 49.9; $\mathrm{SD}, 2.1$ ), with an average of 2 years of college and an average verbal IQ of 116.8 (SD, 10.5). Table 1 reports demographic characteristics of the sample in men and by reproductive stage in women. Groups were comparable on body mass index, education, parental socioeconomic status, estimated verbal IQ, and ethnicity. Although age ranges and mean age were similar across groups (differing, on average, by $<18$ months), a group difference in age was significant $\left(F_{(3,182)}=2.8, p=0.04, \eta^{2}=0.04\right)$, showing that premenopausal women were younger than postmenopausal women $\left(t_{(61)}=-2.96, p=0.009\right)$ and men $\left(t_{(124)}=\right.$ $-2.5, p=0.013)$. Thus, all analyses included chronological age as a covariate. Perimenopausal and postmenopausal women and men did not differ significantly from one another (all $p$ values $>0.2$ ).

Neuropsychological and mood assessments indicated that groups did not differ on verbal fluency (composite of FAS and categories, $\left.F_{(3,181)}=0.40, p=0.75\right)$, digit span (backward, $F_{(3,181)}=$ $0.97, p=0.41)$, state anxiety $\left(F_{(3,181)}=0.09, p=0.96\right)$, trait anxiety $\left(F_{(3,181)}=0.17, p=0.92\right)$, or mood scores from the POMS (subscores for tension-anxiety, depression-dejection, vigor-activity, fatigue-inertia, confusion-bewilderment, anger-hostility; all $F<1.7$, $p>0.2$ ). Performance on two episodic memory tests, the Face Name Associative Memory Exam (Rentz et al., 2011; Papp et al., 2014; Face-Name) and six-trial SRT (Masur et al., 1989), differed by sex and reproductive stage. These findings were reported in detail previously (Rentz et al., 2016). To summarize, in aggregate, women outperformed men on both the Face Name test (free recall, $t_{(184)}=$ -3.26, $p<0.001$, two-tailed, $r=0.23$ ) and SRT (delayed recall, $t_{(183)}=-4.15, p<0.0001$, two-tailed, $\left.r=0.28\right)$. However, subsequent analysis revealed that the Face Name test performance differed by reproductive stage (adjusted for age; $F_{(3,179)}=5.85, p=0.001$, partial $\eta^{2}=0.09$ ), with postmenopausal women (mean, 9.34; SE, 0.73 ) performing worse than premenopausal women (mean, 11.75; SE, $0.72 ; p=0.021$ ) and perimenopausal women (mean, 11.67; SE, $0.76 ; p=0.028$ ), but not significantly different from men (mean, 8.93; SE, $0.42 ; p=0.62)$. A similar pattern was observed with the SRT task (Rentz et al., 2016). Medication use was determined by structured clinical interview and medical history information. Psychotropic medication use was uncommon and similarly distributed across groups: benzodiazapines ( 3 premenopausal, 2 perimenopausal, 3 postmenopausal women, 9 men) and antidepressants (selective serotonin reuptake inhibitors; 7 premenopausal, 3 perimenopausal, 4 postmenopausal women, 5 men). Nonpsychotropic medications consisted of those used as a preventative measure for cardiac-related symptoms, e.g., statins ( 9 premenopausal, 10 perimenopausal, 10 postmenopausal women, $43 \mathrm{men}$ ).

\section{Hormonal evaluations}

Analysis of sex steroid hormones and gonadotropins confirmed that serum estradiol $\left(F_{(2,89)}=35.35, p<0.001, r=0.67\right)$ and 

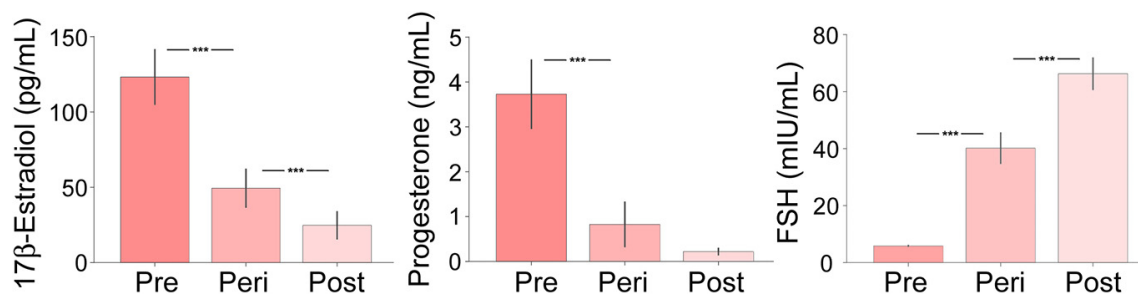

However, group differences emerged after taking into account the reproductive status of women. Significant changes in hippocampal activity were observed as a function of women's reproductive stage, independent of chronological age. Taskevoked activity in left hippocampus decreased over the menopausal transition $\left(F_{(2,85)}=3.5, p=0.035, r=0.28\right)$, with premenopausal (mean, 0.28 ; SE, $0.06 ; p=$ 0.016 ) and perimenopausal (mean, 0.23 ; SE, $0.06 ; p=0.043$ ) women exhibiting greater activity relative to postmeno-

A

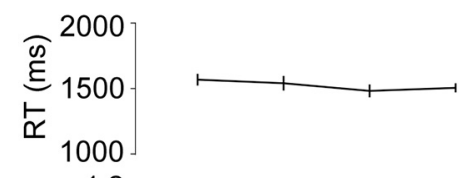

B
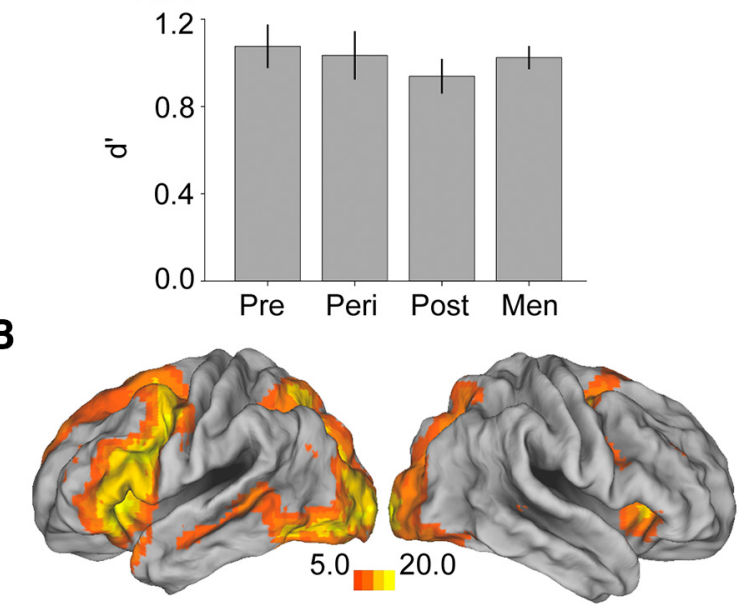

Figure 2. Verbal encoding circuitry and subsequent memory retrieval performance. $A$, Memory retrieval response time (RT) and accuracy (discriminability index, $d^{\prime}$ ) by group. $B$, Task-evoked BOLD responses throughout verbal encoding circuitry, Novel $>$ Repeat, displayed at $p<10^{-16}(N=194)$. Error bars represent \pm 1 SEM. Pre, Premenopause $(n=32)$; Peri, perimenopause $(n=29)$; Post, postmenopause $(n=31)$; $\operatorname{men}(n=94)$.

progesterone $\left(F_{(2,89)}=12.04, p<0.001, r=0.22\right)$ levels declined, while FSH levels rose $\left(F_{(2,90)}=47.31, p<0.001, r=0.52\right)$ over the menopausal transition (Fig. 1).

\section{Verbal retrieval behavioral performance}

Behavioral performance on the verbal retrieval task was comparable across groups, with no significant differences observed for measures of accuracy (percentage correct, $F_{(3,177)}=0.21, p=$ 0.89 ; $d^{\prime}$ sensitivity index, $\left.F_{(3,177)}=0.29, p=0.93\right)$ or response time $\left(F_{(3,177)}=0.41, p=0.75\right.$; Fig. $\left.2 A\right)$.

\section{Regional BOLD response in VE circuitry}

The verbal encoding paradigm evoked robust responses within memory circuitry regions (Fig. 2B). Region of interest analyses examined group differences in task-evoked activity within VLPFC subdivisions (along a dorsal/posterior to ventral/anterior gradient), hippocampus, and posterior parietal cortex (Fig. 3A). We began by analyzing the data by sex, regardless of women's reproductive status. Adjusting for age and performance, no significant differences between men and women were observed for task-evoked responses within VLPFC or hippocampus (all $F_{(1,173)}<0.7$, all $p>0.4$ ). The only exception was PPC, which men activated more strongly than women $\left(F_{(1,173)}=4.78, p=0.03, r=0.16\right.$; Fig. $\left.3 C\right)$. pausal women (mean, 0.03; SE, 0.06; Fig. 3B). Linear regression analyses indicated that, controlling for age, as endogenous estradiol concentrations declined, the magnitude of left hippocampal activity decreased $(\beta=0.15, t=2.0, p=0.05)$. Univariate activity in VLPFC and PPC did not differ by women's reproductive status (all $F<1.3, p>0.3$ ).

\section{Functional connectivity during verbal encoding}

Generalized psychophysiological interaction analyses examined group differences in verbal encoding-dependent connectivity from two seed regions, dorsal VLPFC and hippocampus. Analyses by sex revealed stronger intra-VLPFC connectivity in men. Clusters in ventral/anterior VLPFC displayed greater functional connectivity with the dorsal VLPFC seed in men relative to women (coordinates of peak voxel, $-33,29,-8$; peak-level $p_{\mathrm{FWE}}$ $c_{\text {orrected }}=0.008$; cluster-level $p_{\text {FWE corrected }}=0.018$; Fig. $4 A$ ). Men also showed evidence of heightened connectivity between VLPFC and bilateral inferior parietal lobule (BA40) relative to women. Two clusters (left PPC, -51, - 43, 49; right PPC, 54, -49, 52) showed trend-level significance at $p_{\mathrm{FWE}}$ corrected $=0.08$. At a threshold of $p_{\text {FWE corrected }}<0.05$, no clusters showed stronger connectivity with the VLPFC seed in women (as a whole) compared to men.

In contrast, women (as a whole) showed greater encodingrelated connectivity between the left hippocampal seed and right hippocampus (coordinates of peak voxel, 33, -25, -14; peaklevel $p_{\mathrm{FWE} \text { corrected }}=0.045$; cluster-level $p_{\mathrm{FWE} \text { corrected }}=0.04$ ). However, analyzing data with respect to women's reproductive stage revealed that bilateral hippocampal activity was driven by postmenopausal women, who displayed heightened connectivity relative to premenopausal women, perimenopausal women, and men (all peak-level and cluster-level $p_{\text {FWE corrected }}<0.05$; Fig. $5 A, B)$. Relative to premenopausal women, postmenopausal women showed heightened connectivity between left hippocampus and three right hippocampal clusters: $21,-10,-26$ (peaklevel $p_{\text {FWE corrected }}=0.007$; cluster-level $\left.p_{\text {FWE corrected }}=0.027\right) ; 27$, $-40,-2$ (peak-level $p_{\text {FWE corrected }}=0.033$; cluster-level $\left.p_{\text {FWE corrected }}=0.042\right) ; 21,-10,-26$ (peak-level $p_{\text {FWE corrected }}=$ 0.041 ; cluster-level $\left.p_{\mathrm{FWE} \text { corrected }}=0.042\right)$. Relative to perimenopausal women, postmenopausal women showed greater connectivity with one right hippocampal cluster: $21,-10,-26$ (peak-level $p_{\text {FWE corrected }}=0.029$; cluster-level $p_{\text {FWE corrected }}=$ 0.042 ). Finally, relative to men, postmenopausal women showed greater connectivity with two clusters in right hippocampus: 21, $-10,-26$ (peak-level $p_{\mathrm{FWE}}$ corrected $=0.011$; cluster-level $p_{\text {FWE corrected }}=0.033$ ) and $30,-25,-17$ (peak-level $p_{\text {FWE corrected }}=0.013$; cluster-level $\left.p_{\text {FWE corrected }}=0.022\right)$.

To plot the magnitude of bilateral hippocampal connectivity across groups and control for chronological age, mean $\beta$ values were extracted from the entire right hippocampal mask (542 vox- 
A

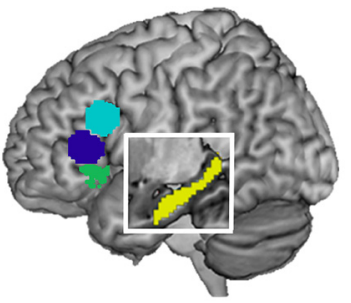

B

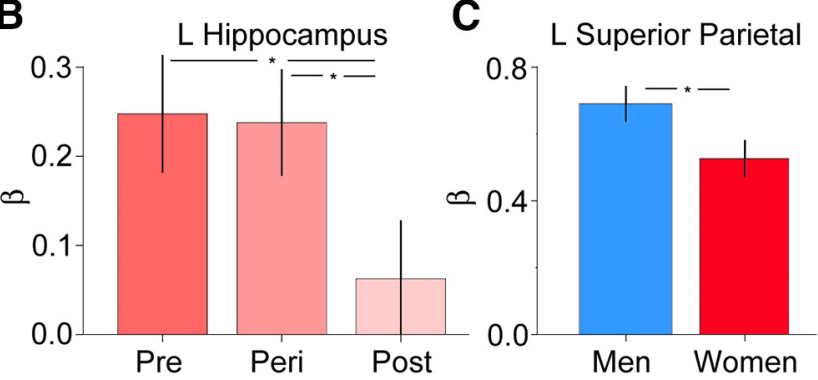

Figure 3. Modulation of verbal encoding-related fMRI BOLD activity in midlife by menopausal status and sex. $A$, Surface location of functionally defined masks of VLPFC subdivisions, BA44/BA45/BA9 (turquoise), BA45 (dark blue), BA47 (green), and posterior parietal (BA7, orange) on a rendered brain. Functional ROIs were generated from a supergroup activity map (Novel-Repeat; $N=194$ ). The white box reveals a cutout of the anatomically defined left hippocampal mask (yellow). $\boldsymbol{B}$, Task-evoked activity in left hippocampus decreased over the transition to menopause. Premenopausal $(n=32)$ and perimenopausal $(n=29)$ women exhibited greater activity relative to postmenopausal women $(n=31)$. C, Men $(n=94)$ showed greater activity in left posterior parietal cortex relative to women $(n=92)$, regardless of menopausal stage. Parameter estimates are adjusted for chronological age. Error bars represent \pm 1 SEM. ${ }^{*} p<0.05$.

\section{Men > Women}
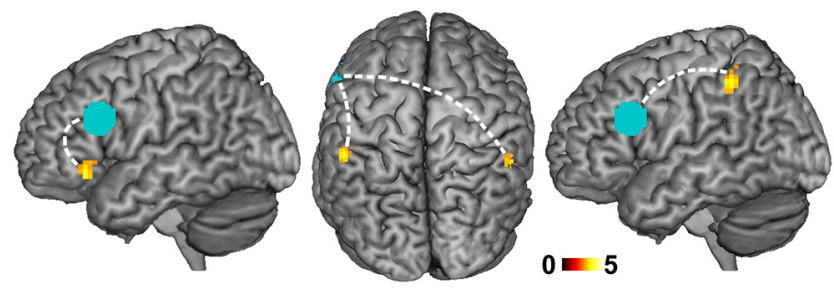

Figure 4. Functional connectivity within encoding circuitry by sex. Left, Relative to women ( $n=92)$, men $(n=94)$ showed greater functional connectivity between dorsal VLPFC (turquoise seed) and ventral VLPFC (BA47, coordinate of peak voxel, $-33,29,-8$; cluster significant at $p<0.05$, FWE corrected). (enter, Right, Men also exhibited greater connectivity between the VLPFC seed and two clusters in bilateral posterior parietal cortex. Clusters in left $\mathrm{BA} 40(-51,-43,49)$ and right BA40 $(54,-49,52)$ reached trend significance at $p=0.08$, FWE corrected. To illustrate the spatial extent of the pattern of connectivity, clusters are displayed at $p<0.005$, uncorrected.

els) to avoid biasing the results by selecting clusters known to differ across groups. The magnitude of connectivity between the left hippocampal seed region and right hippocampal ROI (averaged across all voxels) showed a similar impact of menopausal group $\left(F_{(3,184)}=3.58, p=0.015, r=0.24\right)$, partialling out variance attributable to age. Post hoc comparisons confirmed that postmenopausal women exhibited greater bilateral hippocampal connectivity compared to premenopausal women (mean, -0.21 ; $\mathrm{SD}, 0.54 ; p=0.002$ ), perimenopausal women (mean, $-0.04 ; \mathrm{SD}$, $0.61 ; p=0.053$ ), and men (mean, -0.07 ; S , 0.52; $p=0.007$; Fig. $5 B)$. Finally, to investigate the role of gonadal hormones in shaping bliateral hippocampal connectivity in women, mean PPI $\beta$ values from the right hippocampal mask (representing the magnitude of functional connectivity with the left hippocampal seed) were related to estradiol concentrations. Linear regression anal-
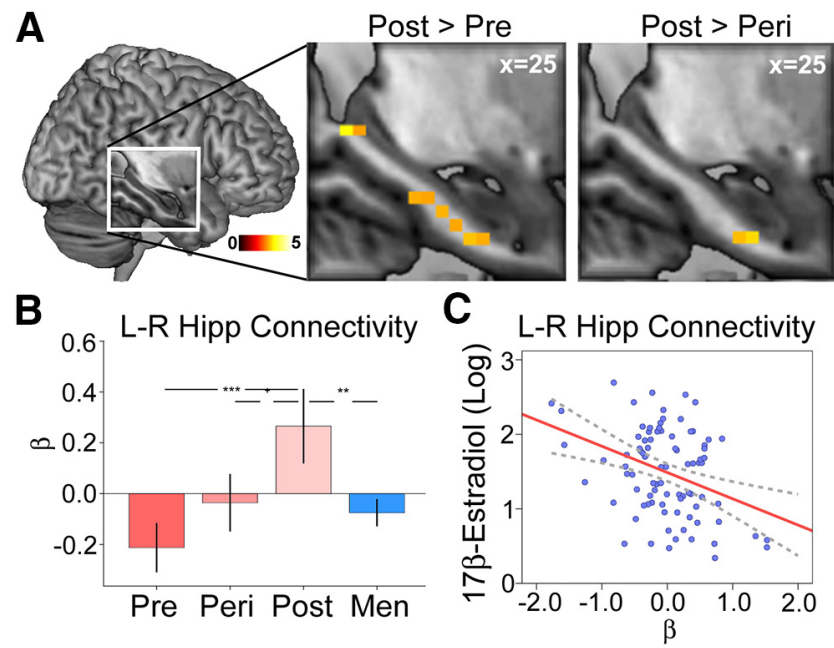

Figure 5. Hippocampal functional connectivity by menopausal status. $\boldsymbol{A}$, Left, A slice through right hippocampus (white box) is visible on a rendered brain. Right, Postmenopausal women ( $n=31$ ) showed greater connectivity between the left hippocampal seed and multiple clusters in right hippocampus relative to premenopausal $(n=32)$ and perimenopausal $(n=$ 29) women (all significant at $p<0.05$, FWE corrected; for coordinates, see Results). Clusters are displayed at $p<0.005$, uncorrected. $\boldsymbol{B}$, Beta values extracted from the entire right hippocampal mask (542 voxels) represent the average magnitude of connectivity between left $(\mathrm{L})$ and right $(R)$ hippocampus during verbal encoding. Bilateral hippocampal connectivity increased over the menopausal transition. Men shown for comparison. C, Scatter plot displays the correlation between endogenous estradiol concentrations (log transformed) and the magnitude of bilateral hippocampal connectivity in women. As estradiol concentrations decline, the magnitude of bilateral hippocampal connectivity increases. Pre, Premenopause; Peri, perimenopause; Post, postmenopause. Gray dotted lines represent $95 \% \mathrm{Cl}$. Error bars represent \pm 1 SEM. ${ }^{+} p<$ $0.06 ;{ }^{* *} p<0.01 ;{ }^{* * *} p<0.005$.

yses indicated that, controlling for age, as estradiol levels declined, the magnitude of left-right hippocampal connectivity substantially increased $\left(F_{(2,86)}=8.89, p<0.001, r=0.42\right.$; estradiol, $\beta=-0.57, t=-3.76, p<0.001$; Fig. $5 C)$. This association was not observed for progesterone $\left(F_{(2,86)}=0.78, p=0.65\right)$.

In sum, during verbal memory encoding, men showed heightened intra-VLPFC functional connectivity (from more dorsal/ posterior to ventral/anterior subdivisions) and some evidence of greater PFC-PPC connectivity relative to women. In contrast, women showed heightened bilateral hippocampal connectivity as a function of advanced menopausal status and declining estradiol levels, independent of chronological age.

Finally, to further investigate the altered pattern of hippocampal functional connectivity in postmenopausal women, participants were subdivided into tertiles of "low" $(n=10)$, "middle" $(n=11)$, and "high" $(n=10)$ performers based on a composite index of performance on the Face Name Associative Memory task (Fig. 6A), a task shown previously to be sensitive to early changes in memory function (Rentz et al., 2011; Hedden et al., 2012). Within postmenopausal women, the highest performers showed the least recruitment of contralateral right HIPP (i.e., smallest magnitude of left-right hippocampal connectivity; $F_{(2,30)}=4.3$, $p=0.024, r=0.49$; Fig. $6 B$ ). Post hoc comparisons revealed that high performers (mean, -0.28 ; SD, 0.57 ) differed significantly from low (mean, $0.67 ; \mathrm{SD}, 1.0 ; p=0.007$ ) and middle (mean, 0.38 ; SD, $0.52 ; p=0.045$ ) performers, while low and middle tertiles did not differ from one another $(p=0.39)$. In addition, postmenopausal women with preserved memory function recruited VLPFC (BA45) more strongly than poorer performing subjects $\left(F_{(2,30)}=3.36, p=0.050\right.$; high vs low, $p=0.056$; high vs middle, $p=0.023$; Fig. $6 C)$. 

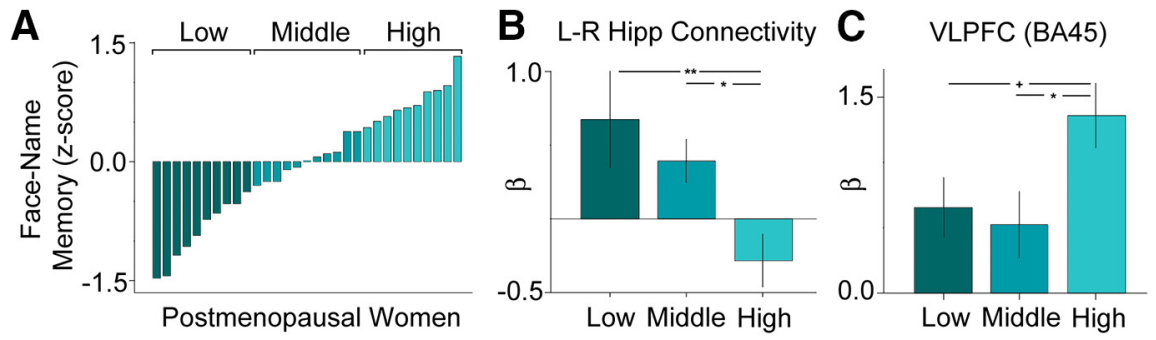

Discussion

Figure 6. High-performing postmenopausal women show the least bilateral hippocampal connectivity and enhanced VLPFC activity relative to low performers. $A$, Postmenopausal women were categorized into tertiles of low $(n=10)$, middle $(n=11)$, and high $(n=10)$ performers based on a composite summary score of the Face Name Associative Memory Task (see Materials and Methods). $\boldsymbol{B}, \boldsymbol{C}$, High-performing women showed the least functional connectivity between left $(\mathrm{L})$ and right ( $\mathrm{R}$ ) hippocampus $(\boldsymbol{B})$ and the greatest recruitment of VLPFC relative to the two lower performing tertiles (C). Error bars represent \pm 1 SEM. ${ }^{+} p<0.06$; ${ }^{*} p<0.05 ;{ }^{* *} p<0.01$.

A
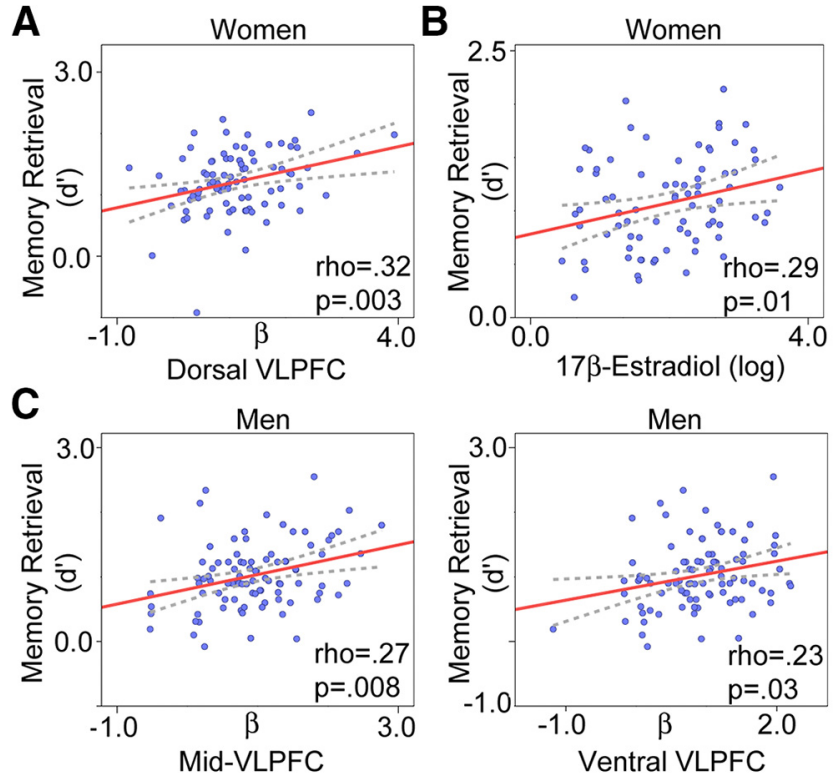

Figure 7. Relationship between VLPFC activity and memory retrieval in women and men. $A, C$, Scatter plots display the correlation between the magnitude of encoding-related activity ( $\beta$ value) in VLPFC subdivisions and performance on a subsequent memory retrieval task. $A$, In women $(n=92)$, the magnitude of activity in dorsal VLPFC (BA44/BA45/BA9) predicted better memory retrieval. $\boldsymbol{B}$, Higher estradiol levels were also associated with better retrieval in women. $C$, In men $(n=94)$, activity in mid (BA45) and ventral (BA47) VLPFC subdivisions was associated with more successful retrieval. Gray dotted lines represent $95 \%$ Cls.

\section{Brain-hormone-behavior relationships}

The magnitude of encoding-related activity within memory circuitry was strongly related to subsequent memory retrieval. In men, regional activity in mid-VLPFC (BA45; $\rho=0.27 ; 95 \%$ CI, $0.04-0.47 ; p=0.008$, two-tailed; $n=94)$ and ventral/anterior VLPFC (BA47; $\rho=0.23 ; 95 \%$ CI, 0.01-0.42; $p=0.03$, twotailed) was related to more successful memory retrieval performance. For women, better retrieval was related to activity in dorsal/posterior VLPFC (BA44/BA45/BA9; $\rho=0.32 ; 95 \%$ CI, $0.11-0.52 ; p=0.003$, two-tailed; $n=91$; Fig. $7 A, C)$. With respect to gonadal hormones, in women, successful retrieval was related to higher endogenous estradiol levels ( $\rho=0.29 ; 95 \%$ CI, $0.06-0.49 ; p=0.011$, two-tailed; Fig. $7 B$ ). In men, a similar pattern emerged with higher testosterone levels related to better memory retrieval, but the findings were not statistically significant, in part due to low variability of testosterone among the men $(\rho=0.13 ; 95 \%$ CI, $-0.04-0.35 ; p=0.13)$.

\section{Summary of findings}

Cognitive aging studies traditionally target participants aged 65 and older, yet epidemiological surveys show that many women report increased forgetfulness and "brain fog" earlier in the aging process, as they transition through menopause (Greendale et al., 2011). In this population-based fMRI study, we stepped back by over a decade to characterize the changes in memory circuitry that occur in early midlife (age $\sim 45-55$ ) as a function of sex and women's menopausal status. Women's reproductive stage shaped taskevoked hippocampal activity during verbal memory encoding, despite minimal variance in chronological age. Premenopausal and perimenopausal women recruited left hippocampus more strongly than postmenopausal women. Next, using generalized psychophysiological interaction analysis, we explored the impact of reproductive stage on integrated activity across task-related brain regions. Analyses within women revealed a reorganization of functional networks across the menopausal transition. Postmenopausal women showed heightened bilateral hippocampal connectivity relative to premenopausal and perimenopausal women. Furthermore, the magnitude of regional activity and functional connectivity during encoding was related to verbal memory retrieval.

While the influence of menopausal status was greatest in the hippocampus, a number of sex differences were observed in prefrontal and parietal cortices, which were independent of women's reproductive stage. For example, men showed greater taskevoked activity in left PPC and heightened VLPFC-PPC functional connectivity relative to women. Critically, analyzing these data without regard to sex obscured group differences in the circuit-level neural strategies associated with successful memory performance.

At the neuroendocrine level, lower $17 \beta$-estradiol was related to more pronounced alterations in hippocampal activity, hippocampal connectivity, and poorer performance on a subsequent memory task, strongly implicating sex steroids in the regulation of this circuitry. Subgroup analyses revealed that highperforming postmenopausal women (relative to low and middle performers) exhibited a neuronal response pattern similar to that of premenopausal women. Together, these findings underscore the importance of considering reproductive stage and sex steroid hormones, not simply chronological age, to identify neuronal and cognitive changes that unfold in the middle decades of life. More broadly, these findings suggest that early changes in memory circuitry are evident decades before the age range typically targeted by cognitive neuroscience of aging studies.

\section{Study design and limitations}

Given that chronological age differed marginally between groups $(<18$ months, on average), the observed differences in taskevoked BOLD responses are unlikely to be attributable to agerelated changes in cerebral vasculature (D'Esposito et al., 2003). Furthermore, the impact of reproductive status on BOLD was region-specific and thus not likely driven by global changes in blood oxygenation. One limitation of this study is its crosssectional design, which precluded our ability to directly assess incremental changes over the transition to menopause. However, by using a midlife cohort for whom chronological age was similar 
but menopausal status varied, we were better able to tease apart the influence of reproductive aging from chronological aging. Second, medical histories indicated that some participants in our midlife cohort reported use of a prescription drug. To limit confounding effects of medication status, we ensured that psychotropic medication use, while uncommon, was evenly distributed across groups. Furthermore, plotting ROI $\beta$ estimates by medication status and group produced highly comparable values across every region of interest. This ensured us that medication status was unlikely to be driving the observed findings.

\section{Changes in memory circuitry are evident in midlife}

Despite the tradition in the aging literature of studying adults 65 and older, more attention is being paid to the neural and cognitive changes that happen in the preceding decades, as adults enter midlife. Previous findings suggest that changes in memory encoding and retrieval ability and related neural activity are evident by midlife (Park et al., 2013; Cansino et al., 2015; Kwon et al., 2015). During source encoding, Cansino et al. (2015) observed underrecruitment of prefrontal regions in middle aged relative to younger adults. During spatial and temporal context memory, Kwon et al. (2015) observed no difference in encoding-related brain activity, but heightened PFC activation in middle aged adults during retrieval. Across the small handful of functional MRI studies to investigate memory function in midlife, none reported changes in middle temporal lobe regions (when performance is matched across groups), and changes in PFC function are less consistent across studies (Kennedy et al., 2012; Grady et al., 2006; Kwon et al., 2015). Although these studies represent a critical step toward characterizing early changes in memory circuitry, none of the studies examined their findings with respect to sex or women's reproductive stage. Given that this time period marks one of the most significant periods of hormonal change for women, and given the role of sex steroid hormones in regions central to memory encoding and retrieval processes, considering women's menopausal status may be critical for fully understanding the changes in memory circuitry that take place in midlife. In fact, one of the most consistently observed cognitive changes in women transitioning through menopause is in the domain of verbal learning and memory (Berent-Spillson et al., 2012; Epperson et al., 2013). Advancing our understanding of the hormonal regulation of memory circuitry may provide insights as to why women are at higher risk for memory disorders later in life (Mielke et al., 2014).

\section{Sex differences in midlife}

Although no differences were observed in VLPFC as a function of reproductive stage, we observed an overall sex difference in this region in our midlife cohort, with men showing stronger functional connectivity within VLPFC (from dorsal to ventral subdivisions) and between VLPFC and PPC relative to women. We also found that subdivisions of VLPFC were differentially associated with verbal retrieval performance in men and women, with women reliant on dorsal subregions (bordering BA44/BA45/ BA9) and men reliant on middle and ventral subregions (BA45 and BA47). Findings from the resting-state literature suggest that these VLPFC subdivisions are part of different functional networks, with the dorsal VLPFC region falling within the dorsal frontoparietal attention network and the more anterior/ventral VLPFC regions falling within the ventral controlled retrieval network (which includes the hippocampus; Nyhus and Badre, 2015). Although speculative, this hints that men and women may be relying on different neural strategies (represented here as different functional networks) to successfully perform the task.

\section{Reproductive stage and estradiol impact hippocampal function}

Previous cognitive aging studies found age-related underrecruitment of left VLPFC during episodic encoding (Spaniol and Grady, 2012). Age-related changes in bilateral parietal cortex have also been observed, with greater encoding-related activity in older versus younger adults (unmatched for performance; Sperling et al., 2003; Grady et al., 2006; Murty et al., 2006). In this study, neither VLPFC nor PPC activity differed as a function of reproductive age in women, despite differences in hippocampal activity over this same period. This suggests that the hippocampus may be more sensitive to the impact of reproductive aging than VLPFC or PPC. From a neuroendocrine perspective, this makes sense given that the hippocampus contains some of the highest concentrations of $\mathrm{ER} \alpha$ and $\mathrm{ER} \beta$ in the brain (second only to hypothalamic nuclei and central medial nucleus of the amygdala; Österlund et al., 1999, 2000). In fact, we found that $17 \beta$-estradiol concentrations were related to alterations in hippocampal connectivity and poorer performance on a subsequent memory task across women, strongly implicating sex steroids in the modulation of hippocampal function. We did not find evidence of a relationship between progesterone and hippocampal activity, but our data do not rule out the possibility that additional gonadal hormones, including progesterone and its neurosteroid metabolites, contribute to the observed effects. Future studies should examine reproductive age-related changes using more challenging episodic memory tasks, such as tasks that rely on context memory as opposed to item recognition. Doing so may reveal functional differences across a broader network of regions, including PFC (Kwon et al., 2015).

\section{High-performing postmenopausal women show premenopausal-like pattern of neural activity}

The purpose of this study was to characterize the impact of menopausal status on memory circuitry function. However, an important exploratory question is whether some women progress through menopause but retain a pattern of brain activity akin to premenopausal women and show elevated cognitive function in domains known to decline as a function of reproductive stage (Epperson et al., 2013; Rentz et al., 2016). To address this, we used an individual-differences driven approach to test whether memory circuitry function differed between low- and highperforming postmenopausal women. Using a strategy similar to previous aging studies (Gazzaley et al., 2005), we defined tertiles of low, middle, and high performers based on the 12-item Face Name Associative Memory Exam. This task was chosen because of its increased sensitivity for detecting early changes in memory function (Rentz et al., 2011, 2016). On average, postmenopausal women showed heightened bilateral hippocampal connectivity during encoding relative to premenopausal and perimenopausal women. However, subgroup analysis revealed that this heightened connectivity was characteristic of low and middle performers and uncharacteristic of postmenopausal women with preserved memory function.

Ample preclinical evidence demonstrates that the decline in ovarian estradiol production during menopause leads to neuronal changes in the hippocampus. For example, Hara et al., 2012 showed that natural menopause in female macaques results in a lower density of perforated synapse spines in the hippocampus and worse recognition memory. Our data support and extend 
this literature by demonstrating alterations in hippocampal function in women as a function of reproductive stage. Our data are consistent with estradiol's general role in modulating hippocampal function. However, an outstanding question is how the subgroup of high-performing postmenopausal women compensated even in the face of low estradiol. Note that in our sample, low, middle, and high performers did not differ in demographic characteristics (e.g., age, body mass index, socioeconomic status), estradiol and progesterone concentrations, or the number of years since their final menstrual period. One possibility is that as ovarian sources of estradiol decline, secondary estrogenic support from other peripheral sources may play a role in maintaining hippocampal function and hippocampal-dependent memory performance. For high-performing women, the loss of ovarian estradiol may be compensated for through other endocrine pathways, a possibility we are currently pursuing.

Moving forward, understanding the cellular, synaptic, and circuit-level mechanisms for maintaining memory function in the face of reduced ovarian function is a critical challenge for future research, given the potential for identifying therapeutic targets (Frick, 2012). Identifying the distinguishing characteristics between low and high performers will be an important step toward understanding divergent trajectories of cognitive aging as they unfold in the middle years of life.

\section{Conclusions}

These results contribute to our broader understanding of the impact of sex and reproductive status on the aging of memory circuitry. In keeping with preclinical studies, our findings suggest that the loss of ovarian estradiol during menopause plays a significant role in shaping memory circuitry.

\section{References}

Abbs B, Liang L, Makris N, Tsuang M, Seidman LJ, Goldstein JM (2011) Covariance modeling of MRI brain volumes in memory circuitry in schizophrenia: Sex differences are critical. Neuroimage 56:1865-1874. CrossRef Medline

Adams MM, Fink SE, Shah RA, Janssen WG, Hayashi S, Milner TA, McEwen BS, Morrison JH (2002) Estrogen and aging affect the subcellular distribution of estrogen receptor-alpha in the hippocampus of female rats. J Neurosci 22:3608-3614. Medline

Bailey ME, Wang AC, Hao J, Janssen WG, Hara Y, Dumitriu D, Hof PR, Morrison JH (2011) Interactive effects of age and estrogen on cortical neurons: implications for cognitive aging. Neuroscience 191:148-158. CrossRef Medline

Benton AL (1968) Differential behavioral effects in frontal lobe disease. Neuropsychologia 6:53-60.

Berent-Spillson A, Persad CC, Love T, Sowers M, Randolph JF, Zubieta JK, Smith YR (2012) Hormonal environment affects cognition independent of age during the menopause transition. J Clin Endocrinol Metab 97: E1686-E1694.

Berman KF, Schmidt PJ, Rubinow DR, Danaceau MA, Van Horn JD, Esposito G, Ostrem JL, Weinberger DR (1997) Modulation of cognition-specific cortical activity by gonadal steroids: a positron-emission tomography study in women. Proc Natl Acad Sci U S A 94:8836-8841. CrossRef Medline

Blumenfeld RS, Ranganath C (2007) Prefrontal cortex and long-term memory encoding: an integrative review of findings from neuropsychology and neuroimaging. Neuroscientist 13:280-291.

Boulware MI, Kent BA, Frick KM (2012) The impact of age-related ovarian hormone loss on cognitive and neural function. In: Behavioral neurobiology of aging, pp 165-184. Berlin: Springer.

Brinton RD (2009) Estrogen-induced plasticity from cells to circuits: predictions for cognitive function. Trends in pharmacological sciences, 30(4), 212-222. CrossRef

Buckner RL, Kelley WM, Petersen SE (1999) Frontal cortex contributes to human memory formation. Nat Neurosci 2:311-314.
Cabeza R, Dennis N (2013) Frontal lobes and aging. In Principles of frontal lobe function, Ed 2, pp 628-652. New York: Oxford UP.

Cansino S, Estrada-Manilla C, Trejo-Morales P, Pasaye-Alcaraz EH, AguilarCastañeda E, Salgado-Lujambio P, Sosa-Ortiz AL (2015) fMRI subsequent source memory effects in young, middle-aged and old adults. Behav Brain Res 280:24-35. CrossRef Medline

D'Esposito M, Deouell LY, Gazzaley A (2003) Alterations in the BOLD fMRI signal with ageing and disease: a challenge for neuroimaging. Nat Rev Neurosci 4:863-872. CrossRef Medline

Duff SJ, Hampson E (2000) A beneficial effect of estrogen on working memory in postmenopausal women taking hormone replacement therapy. Horm Behav 38:262-276. CrossRef Medline

Dumas JA, Kutz AM, Naylor MR, Johnson JV, Newhouse PA (2010) Increased memory load-related frontal activation after estradiol treatment in postmenopausal women. Horm Behav 58:929-935. CrossRef Medline

Dumitriu D, Rapp PR, McEwen BS, Morrison JH (2010) Estrogen and the aging brain: an elixir for the weary cortical network. Ann N Y Acad Sci 1204:104-112. CrossRef

Epperson CN, Amin Z, Ruparel K, Gur R, Loughead J (2012) Interactive effects of estrogen and serotonin on brain activation during working memory and affective processing in menopausal women. Psychoneuroendocrinol 37:372-382. CrossRef

Epperson CN, Sammel MD, Freeman EW (2013) Menopause effects on verbal memory: findings from a longitudinal community cohort. J Clin Endocrinol Metab 98:3829-3838. CrossRef

Fortress AM, Frick KM (2014) Epigenetic regulation of estrogen-dependent memory. Front Neuroendocrinol 35:530-549.

Frick KM (2012) Building a better hormone therapy? How understanding the rapid effects of sex steroid hormones could lead to new therapeutics for age-related memory decline. Behav Neurosci 126:29-53. CrossRef

Gao S, Hendrie HC, Hall KS, Hui S (1998) The relationships between age, sex, and the incidence of dementia and Alzheimer disease: a metaanalysis. Arch Gen Psychiatry 55:809-815. CrossRef

Gazzaley A, Cooney JW, Rissman J, D’Esposito M (2005) Top-down suppression deficit underlies working memory impairment in normal aging. Nat Neurosci 8:1298-1300.

Golby AJ, Poldrack RA, Brewer JB, Spencer D, Desmond JE, Aron AP, Gabrieli JD (2001) Material-specific lateralization in the medial temporal lobe and prefrontal cortex during memory encoding. Brain 124:1841-1854.

Grady C (2012) The cognitive neuroscience of ageing. Nat Rev Neurosci 13:491-505. CrossRef

Grady CL, Craik FI (2000) Changes in memory processing with age. Curr Opin Neurobiol 10:224-231.

Grady CL, Springer MV, Hongwanishkul D, McIntosh AR, Winocur G (2006) Age-related changes in brain activity across the adult lifespan. J Cogn Neurosci 18:227-241. CrossRef

Greendale GA, Derby CA, Maki PM (2011) Perimenopause and Cognition. Obstet Gynecol Clin North Am 38:519-535. doi:10.1016/j.ogc.2011.05.007.

Grigorova M, Sherwin BB, Tulandi T (2006) Effects of treatment with leuprolide acetate depot on working memory and executive functions in young premenopausal women. Psychoneuroendocrinology 31:935-947. CrossRef

Grober E, Lipton RB, Hall C, Crystal H (2000) Memory impairment on free and cued selective reminding predicts dementia. Neurology 54:827-832. CrossRef Medline

Hampson E, Morley EE (2013) Estradiol concentrations and working memory performance in women of reproductive age. Psychoneuroendocrinology 38:2897-2904. CrossRef

Hao J, Rapp PR, Leffler AE, Leffler SR, Janssen WG, Lou W, McKay H, Roberts JA, Wearne SL, Hof PR, Morrison JH (2006) Estrogen alters spine number and morphology in prefrontal cortex of aged female rhesus monkeys. J Neurosci 26:2571-2578. CrossRef Medline

Hara Y, Park CS, Janssen WG, Roberts MT, Morrison JH, Rapp PR (2012) Synaptic correlates of memory and menopause in the hippocampal dentate gyrus in rhesus monkeys. Neurobiol Aging 33:421-e17. Medline

Harlow SD, Gass M, Hall JE, Lobo R, Maki P, Rebar RW, Sherman S, Sluss PM, de Villiers TJ, STRAW + 10 Collaborative Group (2012) Executive summary of the Stages of Reproductive Aging Workshop + 10: addressing the unfinished agenda of staging reproductive aging. J Clin Endocrinol Metab 97:1159-1168. CrossRef 
Hedden T, Mormino EC, Amariglio RE, Younger AP, Schultz AP, Becker JA, Rentz DM (2012) Cognitive profile of amyloid burden and white matter hyperintensities in cognitively normal older adults. J Neurosci 32:1623316242.

Hogervorst E, Williams J, Budge M, Riedel W, Jolles J (2000) The nature of the effect of female gonadal hormone replacement therapy on cognitive function in post- menopausal women: a meta-analysis. Neuroscience 101: 485-512. CrossRef Medline

Howden LM, Meyer JA (2011) Age and Sex Composition. U.S. Census Bureau 2010 Census Briefs, C2010BR-03. https://www.census.gov/prod/ cen2010/briefs/c2010br-09.pdf.

Jacobs E, D'Esposito M (2011) Estrogen shapes dopamine-dependent cognitive processes: Implications for women's health. J Neurosci 31:52865293. CrossRef

Jacobs EG, Weiss B, Makris N, Whitfield-Gabrieli S, Buka SL, Klibanski A, Goldstein JM (2016) Reorganization of functional networks in verbal working memory circuitry in early midlife: the impact of sex and menopausal status. Cerebral Cortex. Advance online publication. doi:10.1093/ cercor/bhw127. Retrieved August 25, 2016.

Kennedy KM, Rodrigue KM, Devous MD Sr, Hebrank AC, Bischof GN, Park DC (2012) Effects of beta-amyloid accumulation on neural function during encoding across the adult lifespan. Neuroimage 62:1-8.

Koivisto K, Reinikainen KJ, Hanninen T, Vanhanen M, Helkala EL, Mykkänen L, Laakso M, Pyörälä K, Riekkinen PJ Sr (1995) Prevalence of age-associated memory impairment in a randomly selected population from eastern Finland. Neurology 45:741-747. CrossRef

Kwon D, Maillet D, Pasvanis S, Ankudowich E, Grady CL, Rajah MN (2015) Context memory decline in middle aged adults is related to changes in prefrontal cortex function. Cereb Cortex 26:2440-2460. CrossRef

Lemos R, Simões MR, Santiago B, Santana I (2014) The free and cued selective reminding test: Validation for mild cognitive impairment and Alzheimer's disease. J Neuropsychol 9:242-257. CrossRef

Liu F, Day M, Muniz LC, Bitran D, Arias R, Revilla-Sanchez R, Grauer S, Zhang G, Kelley C, Pulito V, Sung A, Mervis RF, Navarra R, Hirst WD, Reinhart PH, Marquis KL, Moss SJ, Pangalos MN, Brandon NJ (2008) Activation of estrogen receptor- $\beta$ regulates hippocampal synaptic plasticity and improves memory. Nat Neurosci 11:334-343. CrossRef Medline

Maki PM, Henderson VW (2012) Hormone therapy, dementia, and cognition: the Women's Health Initiative 10 years on. Climacteric 15:256-262. CrossRef Medline

Makris N, Swaab DF, van der Kouwe A, Abbs B, Boriel D, Handa RJ, Goldstein JM (2013) Volumetric parcellation methodology of the human hypothalamus in neuroimaging: normative data and sex differences. NeuroImage 69:1-10.

Maldjian JA, Laurienti PJ, Kraft RA, Burdette JH (2003) An automated method for neuroanatomic and cytoarchitectonic atlas-based interrogation of fMRI data sets. Neuroimage 19:1233-1239.

Masur DM, Fuld PA, Blau AD, Thal LJ, Levin HS, Aronson MK (1989) Distinguishing normal and demented elderly with the Selective Reminding Test. J Clin Exp Neuropsychol 11:615-630. CrossRef Medline

McEwen BS (2002) Sex, stress and the hippocampus: Allostasis, allostatic load and the aging process. Neurobiol Aging 23:921-939. CrossRef Medline

McLaren DG, Ries ML, Xu G, Johnson SC (2012) A generalized form of contextdependent psychophysiological interactions (gPPI): a comparison to standard approaches. Neuroimage 61:1277-1286. CrossRef Medline

Mielke MM, Vemuri P, Rocca WA (2014) Clinical epidemiology of Alzheimer's disease: assessing sex and gender differences. Clin Epidemiol 6:3748. Medline

Morcom AM, Good CD, Frackowiak RS, Rugg MD (2003) Age effects on the neural correlates of successful memory encoding. Brain 126:213-229. CrossRef Medline

Morrison JH, Baxter MG (2012) The ageing cortical synapse: hallmarks and implications for cognitive decline. Nat Rev Neurosci 13:240-250. Medline

Morrison JH, Brinton RD, Schmidt PJ, Gore AC (2006) Estrogen, menopause, and the aging brain: How basic neuroscience can inform hormone therapy in women. J Neurosci 26:10332-10348. CrossRef Medline

Murty VP, Ritchey M, Adcock RA, LaBar KS (2006) fMRI studies of successful emotional memory encoding: a quantitative meta-analysis. Neuropsychologia 48:3459-3469.
Nelson HE (1982) National Adult Reading Test (NART) test manual. Windsor (UK): NFER-Nelson.

Niswander KR, Gordon MJ (1972) The women and their pregnancies: the Collaborative Perinatal Study of the National Institute of Neurological Diseases and Stroke. National Institute of Health; for sale by the Supt. of Docs., US Govt. Print. Off.

Nyhus E, Badre D (2015) Functional organization of frontal cortex. In: Memory Retrieval and the Functional Organization of Frontal Cortex, $p$ 131. West Sussex, UK: Wiley and Sons.

Österlund MK, Keller E, Hurd YL (1999) The human forebrain has discrete estrogen receptor $\alpha$ messenger RNA expression: high levels in the amygdaloid complex. Neuroscience 95:333-342. CrossRef Medline

Österlund MK, Gustafsson JA, Keller E, Hurd YL (2000) Estrogen receptor $\beta$ (ER $\beta$ ) messenger ribonucleic acid (mRNA) expression within the human forebrain: distinct distribution pattern to ER $\alpha$ mRNA 1. J Clin Endocrinol Metab 85:3840-3846. CrossRef Medline

Papp KV, Amariglio RE, Dekhtyar M, et al (2014) Development of a psychometrically equivalent short form of the Face-Name Associative Memory Exam for use along the early Alzheimer's disease trajectory. Clin Neuropsychol 28:771-785.

Park H, Kennedy KM, Rodrigue KM, Hebrank A, Park DC (2013) An fMRI study of episodic encoding across the lifespan: changes in subsequent memory effects are evident by middle-age. Neuropsychologia 51:448 456. CrossRef Medline

Rajah MN, Maillet D, Grady CL (2015) Episodic memory in healthy older adults. In: The Wiley handbook on the cognitive neuroscience of memory, pp 347-370. West Sussex, UK: Wiley and Sons.

Rapp PR, Morrison JH, Roberts JA (2003) Cyclic estrogen replacement improves cognitive function in aged ovariectomized rhesus monkeys. J Neurosci 23:5708-5714. Medline

Rentz DM, Amariglio RE, Becker JA, Frey M, Olson LE, Frishe K, Carmasin J, Maye JE, Johnson KA, Sperling RA (2011) Face-name associative memory performance is related to amyloid burden in normal elderly. Neuropsychologia 49:2776-2783. CrossRef Medline

Rentz DM, Weiss B, Jacobs EG, Cherkerzian S, Buka S, Remington A, Aizley H, Goldstein JM (2016) Sex differences in episodic memory in early midlife: Impact of reproductive aging. Menopause (in press).

Reuter-Lorenz PA, Park DC (2010) Human neuroscience and the aging mind: a new look at old problems. J Gerontol Ser B Psychol Sci Soc Sci 65:405-415. Medline

Shanmugan S, Epperson CN (2014) Estrogen and the prefrontal cortex: towards a new understanding of estrogen's effects on executive functions in the menopause transition. Hum Brain Mapp 35:847-865. CrossRef Medline

Shaywitz SE, Bennett A, Pugh KR, Fulbright RK, Skudlarski P, Mencl WE, Constable RT, Naftolin F, Palter SF, Marchione KE, Katz L, Shankweiler DP, Fletcher JM, Lacadie C, Keltz M, Gore JC (1999) Effect of estrogen on brain activation patterns in postmenopausal women during working memory tasks. JAMA 281:1197-1202. CrossRef Medline

Sherwin BB (2003) Estrogen and cognitive functioning in women. Endocrine Rev 24:133-151. CrossRef

Sherwin BB (2006) Estrogen and cognitive aging in women. Neuroscience 138:1021-1026. CrossRef Medline

Spaniol J, Davidson PS, Kim AS, Han H, Moscovitch M, Grady CL (2009) Event-related fMRI studies of episodic encoding and retrieval: metaanalyses using activation likelihood estimation. Neuropsychologia 47: 1765-1779.

Sperling RA, Bates JF, Chua EF, Cocchiarella AJ, Rentz DM, Rosen BR, Schacter DL, Albert MS (2003) fMRI studies of associative encoding in young and elderly controls and mild Alzheimer's disease. J Neurol Neurosurg Psychiatry 74:44-50. CrossRef Medline

Spreng RN, Wojtowicz M, Grady CL (2010) Reliable differences in brain activity between young and old adults: a quantitative meta-analysis across multiple cognitive domains. Neurosci Biobehav Rev 34:1178-1194. CrossRef Medline

Stone WS, Thermenos HW, Tarbox SI, Poldrack RA, Seidman LJ (2005) Medial temporal and prefrontal lobe activation during verbal encoding following glucose ingestion in schizophrenia: a pilot fMRI study. Neurobiol Learning Memory 83:54-64.

Uncapher MR, Otten LJ, Rugg MD (2006) Episodic encoding is more than 
the sum of its parts: an fMRI investigation of multifeatural contextual encoding. Neuron 52:547-556. CrossRef Medline

Uncapher MR, Wagner AD (2009) Posterior parietal cortex and episodic encoding: insights from fMRI subsequent memory effects and dualattention theory. Neurobiol Learning Memory 91:139-154.

Wang AC, Hara Y, Janssen WG, Rapp PR, Morrison JH (2010) Synaptic estrogen receptor - a levels in prefrontal cortex in female rhesus monkeys and their correlation with cognitive performance. J Neurosci 30:1277012776. CrossRef Medline

Wechsler D (1997) WAIS-III, Wechsler Adult Intelligence Scale. 3d ed. Administration and scoring manual. New York: The Psychological Corporation.

Whitfield-Gabrieli S (2009) Region of interest extraction (REX) toolbox, $p$ 497. Boston, MA.
Wickens TD (2001) Elementary Signal Detection Theory. Oxford: Oxford University Press.

Woolley CS, Gould E, Frankfurt M, McEwen BS (1990) Naturally occurring fluctuation in dendritic spine density on adult hippocampal pyramidal neurons. J Neurosci 10:4035-4039. Medline

Woolley CS, McEwen BS (1993) Roles of estradiol and progesterone in regulation of hippocampal dendritic spine density during the estrous cycle in the rat. J Comp Neurol 336:293-306. CrossRef Medline

Woolley CS, McEwen BS (1994) Estradiol regulates hippocampal dendritic spine density via an $\mathrm{N}$ - methyl-D-aspartate receptor-dependent mechanism. J Neurosci 14:7680-7687. Medline

Worsley KJ, Friston KJ (1995) Analysis of fMRI time-series revisted-again. Neuroimage 2:173-181. 